\title{
Status of passive environmental dosimetry in Europe
}

Maria A. Duch ${ }^{\mathrm{a}}$, Harald Dombrowski ${ }^{\mathrm{b}}$, Christian Hranitzky $^{\mathrm{c}}$, Philip Kleinau ${ }^{\mathrm{d}}$, Stefan Neumaier ${ }^{b}$, Maria Ranogajec-Komor ${ }^{\mathrm{e}}$, Rafael Rodrigue $z^{f}$

a Universitat Politecnica de Catalunya, Diagonal 647, 08028 Barcelona, Spain

${ }^{\mathrm{b}}$ Physikalisch-Technische Bundesanstalt (PTB), Bundesallee 100, 38116 Braunschweig, Germany

${ }^{c}$ Seibersdorf Labor GmbH, 2444 Seibersdorf, Austria

d Helmholtz Zentrum München, Otto-Hahn-Ring 6, 81739 Munich, Germany

${ }^{e}$ Ruder Boskovic Institute, Bijenicka 54, 10000 Zagreb, Croatia

${ }^{\dagger}$ CIEMAT, Avenida Complutense 40, 28040 Madrid, Spain

\section{Highlights}

- Solid state dosemeters are widely used for Environmental Radiation Monitoring (ERM).

- An EURADOS subgroup (WG3-SG2) which works on passive ERM was inaugurated in 2014.

- On the basis of a survey, data on the status of ERM in Europe was obtained.

- The survey helped to design the first EURADOS intercomparison of area dosemeters.

- Some open questions have been identified (terminology, uncertainty assessment...).

\section{Keywords}

Environmental dosimetry, TLD, OSL, RPL

\section{Abstract}

EURADOS Working Group 3 (WG3) aims at providing information about the correct measurement of the ambient dose equivalent (rate) in the environment and has a specific subgroup (WG3-SG2) that focuses on passive environmental dosimetry. One of the initial tasks of the subgroup was to gain an overview of passive dosimetry practices in Europe. On the basis of a survey carried out by this subgroup in 2013/2014, information on the state-of-the-art was gained, several conclusions were drawn and some open ques- tions have been identified, e.g. the harmonization in the terminology, uncertainty assessment procedures and corrections of measured values by passive dosemeters due to transport and climate. 


\section{Introduction}

EURADOS (www.eurados.org) is a network of more than 50 European institutions and 250 scientists working within the field of dosimetry and radiation monitoring. Working Group 3 (WG3- Environmental Dosimetry) carries out research projects and coor- dinated activities to advance the scientific understanding of envi- ronmental dosimetry. This group especially promotes the technical development of new methods in environmental radiation moni- toring (ERM). Solid state dosemeters are widely used for environ- mental monitoring in the vicinity of nuclear and radiological facilities to assess the external radiation dose to the general public and to demonstrate compliance with regulations on public dose limits (European Basic Safety Standards, Council of the European Union, 2013). In this field of dosimetry, the measurement of small additional doses caused by artificial radiation on top of the natural environmental radiation is a challenge. Environmental radiation monitoring is performed at measurement positions outside facil- ities, in most cases outdoor and without artificial radiation con- tributions the dosemeter should properly measure both the cosmic and terrestrial components of natural radiation.

A specific subgroup (WG3-SG2), which works on passive dosimetry in ERM, was inaugurated in 2014. The first task of the subgroup was to gain an overview of passive dosimetry systems and related measurement practices in Europe.

\section{Materials and methods}

The questionnaire was electronically disseminated by e-mail and made known on the EURADOS webpage. It included 20 ques- tions addressing the following topics:

\subsection{Dosimetry system}

Six questions addressed the main radiological characteristics of the dosimetry systems:

- Measuring quantity $\left(H^{\star}(10)\right.$ or other).

- Radiation type (photons, neutrons).

- Dosemeter properties: detector type (TLD, RPL, OSL, other) and number of detectors within a dosemeter.

- Number of issued dosemeters per measuring period.

- Rated ranges (dose and energy range).

- Preferred term for the dosimetry system (area dosemeter, ambient dosemeter, environmental dosemeter, other).

\subsection{Dose calculation}

The dose can be influenced by different contributions, key ele- ments of the dose assessment methodology are the contributions of the background dose and transport dose, e.g., the transport dose can account for up to a 35\% of the measured dose if the transit period is high compared with the monitoring period (Duch et al., 2008; Ranogajec-Komor et al., 1996).

In addition, detector readings are usually multiplied by many correction factors. For instance, thermoluminescent detectors can suffer an unintentional loss of the latent information, known as fading effect. 
Consequently, several questions addressed these topics:

- Net dose calculation and applied methodology to measure/es- timate the background dose.

- Transport dose correction and applied methodology to measure/ estimate the dose contributions not related to the exposure at the measuring location.

- Fading or climate correction methods.

- Other applied corrections.

- Whether the overall measurement uncertainty is calculated and reported or not.

\subsection{Quality assurance}

Participants were asked about different aspects of quality assurance, especially if they held a formal certification/accredita- tion. Some national authorities recommend the adoption of a quality management system, in particular the ISO/IEC 17025:2005 standard on General requirements for the Competence of Testing and Calibration Laboratories (ISO 17025:2005), but the national authorities may require a type approval.

A fundamental element of quality assurance is the participation in intercomparisons, in particular, the standard ISO 17025 requires the regular participation in intercomparisons. Subsequently, some questions were asked to gain an overview on this area:

- Participation in past intercomparisons.

- Traceability to national standards.

- National type approval of the dosimetry system.

- Compatibility with EN IEC 62387-1 (IEC 62387:2012) and EN ISO 17025 (IEC 17025:2005).

\subsection{Customers and interest in intercomparisons}

The dosimetry services were asked to provide information on other services they provide and on fields of application. Finally, participants were asked about their interest in attending an inter- national intercomparison organized by EURADOS in this area.

\section{Results and discussion}

By the end of 2014, 60 questionnaires had been received from 47 different institutions and 24 different countries. These institutions issue approximately $10^{5}$ area dosemeters per year. 


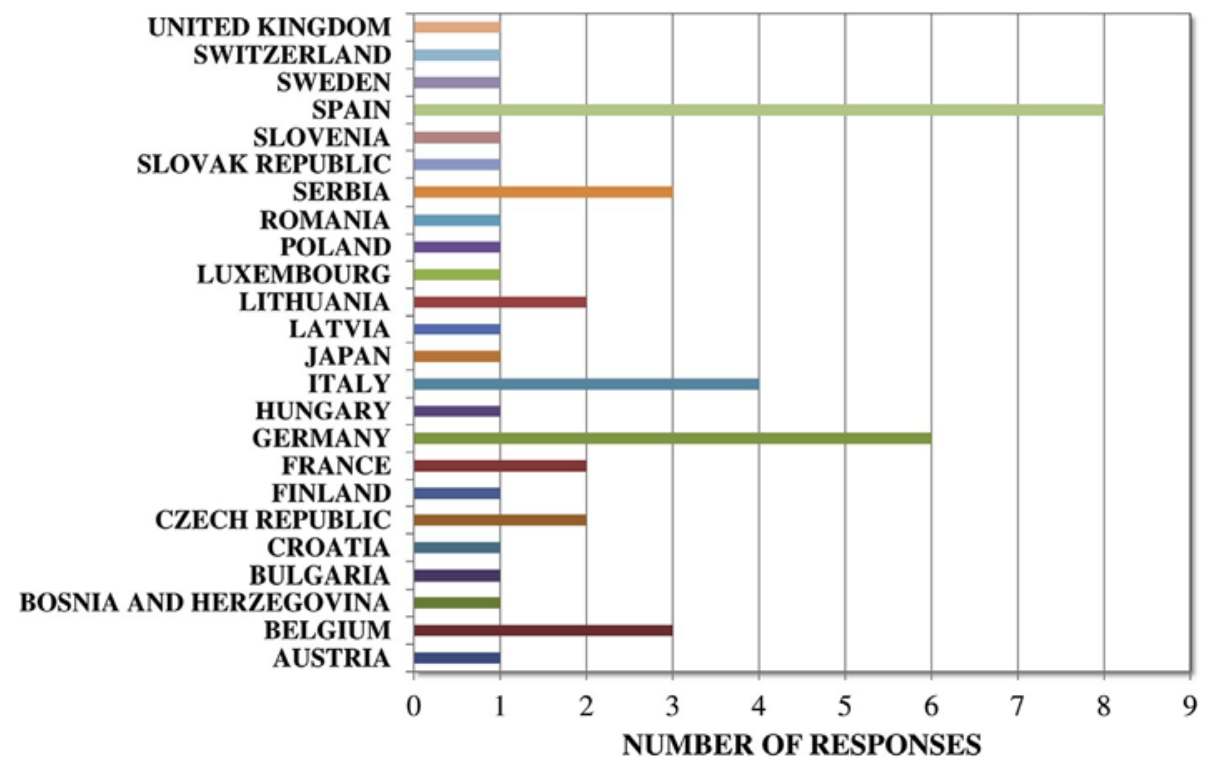

Fig. 1. Number of responses received from various countries.

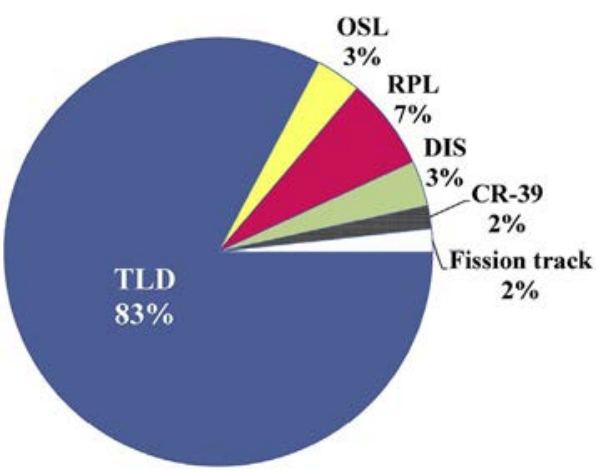

Fig. 2. Types of detectors used in passive environmental dosimetry.

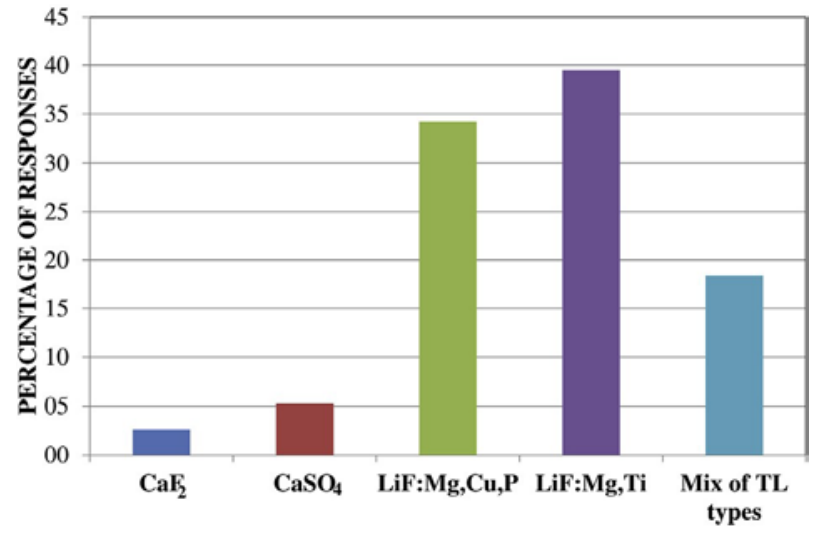

Fig. 3. Types of thermoluminescent detectors used in passive environmental dosimetry. 


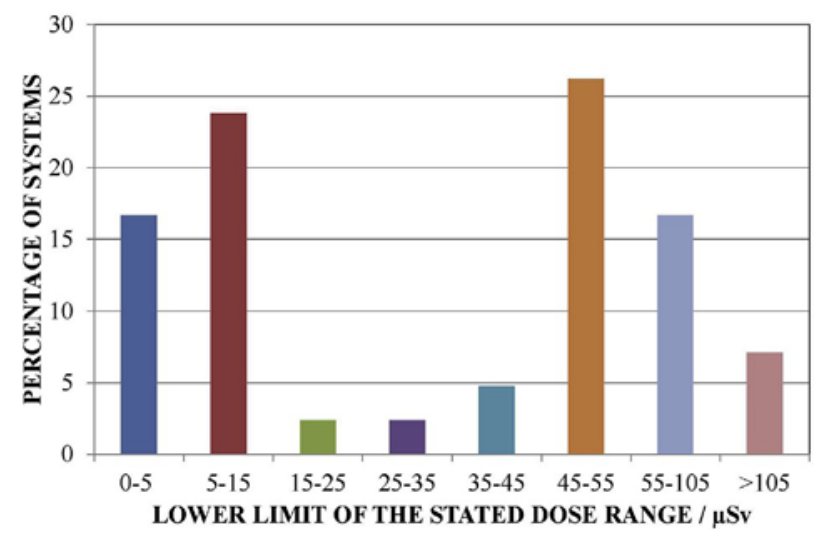

Fig. 4. Lower limit of the stated dose range.

The response representation per country is shown in Fig. 1. Although we did not receive a response from all European coun- tries, the sample covered 21 of the 28 member states and some candidate countries, thus there is a good representation of the European dosimetry services. The response per country was very similar in previous surveys carried out under the roof of EURADOS on individual monitoring systems (Carinou et al., 2014; Gilvin et al., 2014).

The vast majority of dosimetry systems (86\%) used for envi- ronmental monitoring were photon dosimetry systems and only few were neutron/neutron-photon dosimetry systems. The size of the services ranged from very small (fewer than 100 dosemeters issued per measuring period) to very large (more than 4000 dosemeters per measuring period). Three months is the most common monitoring period (67\% of the cases), followed by six months. Other monitoring periods were one, twelve and two months (8\%, $8 \%$ and $5 \%$ respectively).

As regards the dosimetry systems, the systems are based on thermoluminescent (TL) detectors in $83 \%$ of the cases, followed by radiophotoluminescent detectors (RPL) in $7 \%$ of the cases. To a lesser extent, optically stimulated detectors (OSL), direct ion stor- age detectors (DIS), CR-39 and fission track detectors are used (Fig. 2). LiF:Mg,Cu,P emerged in the 80's as a material with signif- icant advantages over LiF:Mg, Ti for environmental dosimetry ap- plications, mainly due to its higher sensitivity, up to 30 times more sensitive than LiF:Mg, Ti (Horowitz, 1993; Ginjaume et al., 1999), however, among the TL systems, LiF:Mg, $\mathrm{Ti}$ is still the most commonly used material (40\%), followed by LiF:Mg,Cu,P (34\%) (Fig. 3). Taking as a reference point the last large-scale international intercomparison of environmental dosemeters organized by the Environmental Measurements Laboratory of the USA (Klemic et al., 1999), where calcium sulphate and LiF:Mg, Ti were the most commonly used TL detector types, the obtained results showed that the use of ultra-sensitive materials is growing up.

The average lower limit of the stated dose range was $54 \mathrm{mSv}$, (Fig. 4). As regards the energy range, the minimum stated lower energy value was $5 \mathrm{keV}$ and the maximum stated lower energy value was $100 \mathrm{keV}$, resulting in $29 \mathrm{keV}$ as the average lower limit of the energy range.

Regarding dose calculation procedures (Table 1), the dosimetry services apply transport dose corrections in half of the cases. Among these, the correction is based on a dose measured with additional passive dosemeters in $69 \%$ of the cases. Only $30 \%$ of the services subtract the natural background from the dosemeter results. 
Only in $43 \%$ of cases the dosimetry services apply fading correction factors. This can be explained by taking into account that the correction factors related to the fading effect are highly dependent on the TL material, the exposure time as well as the ambient temperature. Some materials show a low fading after three months of exposure even at relatively high ambient temperatures, such as LiF:Mg,Cu,P, while other TL materials show very high fading (Ginjaume et al., 1999). Concerning the methods for fading corrections, about half of the services (52\%) apply a fading or climate correction based on estimated values, while additional irradiated dosemeters are used in $39 \%$ of cases. In most cases (83\%), the dosimetry services state that they calculate the overall measure- ment uncertainty.

\begin{tabular}{|c|c|c|c|c|c|c|c|c|c|}
\hline \multicolumn{2}{|c|}{$\begin{array}{l}\text { Do you calculate a net } \\
\text { dose? }\end{array}$} & \multicolumn{2}{|c|}{$\begin{array}{l}\text { Do you apply a } \\
\text { transport correction? }\end{array}$} & \multicolumn{2}{|c|}{$\begin{array}{l}\text { Do you apply a fading } \\
\text { correction? }\end{array}$} & \multicolumn{2}{|c|}{$\begin{array}{l}\text { Do you apply other } \\
\text { corrections? }\end{array}$} & \multicolumn{2}{|c|}{$\begin{array}{l}\text { Do you calculate the } \\
\text { overall uncertainty? }\end{array}$} \\
\hline Yes & No & Yes & No & Yes & No & Yes & No & Yes & No \\
\hline $30 \%$ & $70 \%$ & $49 \%$ & $51 \%$ & $43 \%$ & $57 \%$ & $28 \%$ & $72 \%$ & $83 \%$ & $17 \%$ \\
\hline
\end{tabular}

As regards the quality assurance, most of the services participated in area/environmental dosimetry intercomparisons in the past. The majority of the systems are traceable, and in 66\% of the cases the systems had previously been accredited in compliance with ISO 17025, underlining that there is a wide recognition of the added value and importance of such quality systems.

Finally, there was clear interest to take part in an international intercomparison within this field. In 2014, EURADOS therefore organized the first intercomparison of passive $H^{\star}(10)$ area dose- meters used for environmental radiation monitoring (Dombrowski et al., 2016).

The aim of this intercomparison was to study the long-term behavior of passive dosemeters. WG3-SG2 group decided on the irradiation plan and details of the realization of the intercompar- ison taking into account the results of the survey.

According to the obtained results, it was decided that the 1st Intercomparison exercise should focus on photon dosimetry sys- tems. The irradiations would be performed at dedicated measuring reference sites of the Physikalisch-Technische Bundesanstalt (PTB): the PTB reference measuring site for cosmic radiation (a floating platform on a lake) to measure the response of the dosemeters to secondary cosmic radiation; the reference measuring site for environmental radiation (a free-field installation) to measure the response to terrestrial radiation; and a gamma irradiation facility to check the home calibration in $\mathrm{a}^{137} \mathrm{Cs}$ photon field for a dose level of several mSv. As the transport dose can have a great impact on the final result, the transport dose would be measured very precisely by storing transport dosemeters in the PTB underground laboratory (UDO II) in parallel to the other irradiations, because at this place, the dose accumulated in some months can be neglected. The par- ticipants could choose between an irradiation period of 3 month or 6 month, the most common monitoring periods according to the results of the survey. At the end of the measuring period, partici- pants should report the measured doses without background or transport dose subtraction since the net doses would be calculated by the organizers.

\section{Conclusions}

The survey has provided an overview of passive dosimetry systems used for environmental radiation monitoring in Europe, covering almost all European countries. The results of the survey helped to design the first EURADOS intercomparison of passive $H^{\star}(10)$ 
area dosemeters. The conclusion could be drawn that there is a further need for a harmonization in the field of environmental dosimetry using passive detector systems. Some open questions have been identified, e.g. concerning the harmonization in termi- nology, uncertainty assessment procedures or corrections of measured dose values due to transport and climate. WG3-SG2 will continue to work on these topics in the future.

\section{References}

Carinou, E., Ginjaume, M., O'Connor, U., Kopec, R., Sans Merce, M., 2014. Status of eye lens radiation dose monitoring in European hospitals. J. Radiol. Prot. 34, 729e739. Council of the European Union, 2013. Council Directive 2013/59/Euratom of 5 December 2013 laying down basic safety standards for protection against the dangers arising from exposure to ionising radiation. Official J. Eur. Union L 013, 17 January 2014.

Dombrowski, H., Duch, M.A., Hranitzky, C., Kleinau, P., Neumaier, S., RanogajecKomor, M., Rodriguez, R., 2016. EURADOS Intercomparison of Passive $\mathrm{H}^{*}(10)$ Area Dosemeters2014, 17th Solid State Dosimetry Congress, Munich, Germany.

Duch, M.A., Salez-Vergara, J.C., Ginjaume, M., Gdmez, C., Gonzdlez-Leitdn, A., Herrero, J., de Lucas, M., Rodríguez, R., Marugán, I., Salas, R., 2008. Long-term intercomparison of Spanish environmental dosimetry services. Study of transit dose estimations. Radiat. Meas. 43, 576e579.

Gilvin, P., Alves, J., Cherestes, C., van Dijk, J., Lehtinen, M., Rossi, F., Vekic, B., 2014. Quality assurance in individual monitoring: a summary of the EURADOS survey 2012. Radiat. Meas. 71, 434e437.

Ginjaume, M., Ortega, X., Duch, M.A., Jornet, N., Sảnchez-Reyes, A., 1999. Characteristics of LiF: Mg,Cu, P for clinical applications. Radiat. Prot. Dosim. 85, 389e391. Horowitz, Y.S., 1993. LiF: Mg,Ti versus LiF: Mg,Cu,P: the competition heats up.

Radiat. Prot. Dosim. 47, 135e141.

IEC (International Electrotechnical Committee), 2012. Radiation Protection Instrumentation - Passive Integrating Dosimetry Systems for Personal and Environ- mental Monitoring of Photon and Beta Radiation. IEC International Standard 62387-1, Geneva, Switzerland.

ISO (International Organization for Standardization), 2005. General Requirements for the Competence of Testing and Calibration Laboratories. International Standard ISO no. 17025, Geneva, Switzerland.

Klemic, G., Shobe, J., Sengupta, S., Shebell, P., Miller, K., Carolan, P., Holeman, G., Kanhauser, H., Lamperti, P., Soares, C., Azziz, N., Moscovitch, M., 1999. State of the art of environmental dosimetry: 11th international intercomparison and proposed performance tests. Radiat. Prot. 85, 201e206.

Ranogajec-Komor, M., Vekic, B., Piesch, E., Burgkhardt, B., Szabd, P., 1996. Intercomparison of solid state dosemeters within environmental monitoring. Radiat. Prot. Dosim. 66, 139 e144. 